\title{
Gamma-tubulin and 53BP1 as candidate biomarkers of human papillomavirus-associated anal dysplasia
}

\author{
Ken S Ho ${ }^{1}$, Richard Day ${ }^{2}$, Amy Perkins², Jia Xu², Shih-Fan Kuan ${ }^{3}$, Anette Duensing ${ }^{3,4}$, Ross D Cranston ${ }^{1}$, \\ Stefan Duensing ${ }^{4^{*}}$
}

From $12^{\text {th }}$ International Conference on Malignancies in AIDS and Other Acquired Immunodeficiencies (ICMAOI)

Bethesda, MD, USA. 26-27 April, 2010

\section{Background}

HIV+ men who have sex with men (MSM) are at increased risk of developing anal squamous cell carcinoma. High-grade anal intraepithelial neoplasia (HG-AIN or AIN2/3) is the consequence of persistent infection with high-risk human papillomaviruses and is a precursor to cancer. No biomarkers exist to identify patients with HGAIN at risk of malignant progression. We investigated two candidate biomarkers of genomic instability, gamma-tubulin and 53BP1, in a series of anal biopsies from HIV+ MSM by immunofluorescence microscopy. Gamma-tubulin staining is used to assess centrosome abnormalities as a potential source of cell division errors and aneuploidy, while staining for 53BP1 nuclear foci reflects the presence of DNA double strand breaks.

\section{Materials and methods}

Anal biopsies were obtained from HIV+ MSM undergoing high-resolution anoscopy and reported using the Bethesda 2001 classification system as AIN1 through 3 or carcinoma. Normal colonic tissue served as controls. The percentage of cells with abnormal centrosome number (more than two per cell) and DNA damageassociated 53BP1 foci was assessed and correlated with the histopathological diagnosis. Eighty-eight biopsies were stained for gamma-tubulin, and ninety biopsies were stained for 53BP1.

\footnotetext{
*Correspondence: duensing@pitt.edu

${ }^{4}$ Cancer Virology Program, University of Pittsburgh Cancer Institute,

Pittsburgh, PA, USA

Full list of author information is available at the end of the article
}

\section{Results}

The mean percentage of cells with abnormal centrosomes was $1.5 \%$ in AIN1, $1.3 \%$ in AIN2, and $0.9 \%$ in AIN3. No controls showed centrosome aberrations. A single biopsy diagnosed as carcinoma contained $16.1 \%$ cells with abnormal centrosomes. The mean percentage of cells with abnormal 53BP1 foci was $2.5 \%$ in controls, $17 \%$ in AIN1, $18.5 \%$ in AIN2, and $5.2 \%$ in AIN3. Higher levels of abnormal 53BP1 foci were seen in AIN1 and AIN2 compared to controls based on pair-wise comparisons between control and AIN1 ( $\mathrm{p}=0.0008)$ and control and AIN2 ( $\mathrm{p}=0.0030)$ using the Mann Whitney test. Lower levels of 53BP1 foci were seen in AIN3 compared to AIN1 and 2 based on pair-wise comparisons between AIN1 versus AIN3 ( $\mathrm{p}=0.0034)$ and between AIN2 versus AIN3 $(\mathrm{p}=0.0056)$.

\section{Conclusion}

The levels of centrosome aberrations were generally low in AIN1 through 3 and were increased in carcinoma, suggesting that centrosome abnormalities may not occur until malignant progression. DNA damage-associated 53BP1 foci were increased in AIN1 and 2 when compared to controls, whereas AIN3 showed lower levels of 53BP1 foci. These results are consistent with previous studies suggesting that the DNA damage response represents an early barrier against malignant progression. Further prospective studies assessing the predictive value in particular of 53BP1 as a biomarker in HPVassociated anal neoplasia are warranted. 


\section{Acknowledgements}

This article has been published as part of Infectious Agents and Cancer

Volume 5 Supplement 1, 2010: Proceedings of the $12^{\text {th }}$ International Conference on Malignancies in AIDS and Other Acquired

Immunodeficiencies (ICMAOI). The full contents of the supplement are available online at http://www.biomedcentral.com/1750-9378/5?issue=S1.

\section{Author details}

'Division of Infectious Diseases, University of Pittsburgh, Pittsburgh, PA, USA.

${ }^{2}$ Department of Biostatistics, Graduate School of Public Health, University of

Pittsburgh, Pittsburgh, PA, USA. ${ }^{3}$ Department of Pathology, University of

Pittsburgh School of Medicine, Pittsburgh, PA, USA. ${ }^{4}$ Cancer Virology

Program, University of Pittsburgh Cancer Institute, Pittsburgh, PA, USA.

Published: 11 October 2010

doi:10.1186/1750-9378-5-S1-A29

Cite this article as: Ho et al:: Gamma-tubulin and 53BP1 as candidate

biomarkers of human papillomavirus-associated anal dysplasia. Infectious Agents and Cancer 2010 5(Suppl 1):A29.

\section{Submit your next manuscript to BioMed Central} and take full advantage of:

- Convenient online submission

- Thorough peer review

- No space constraints or color figure charges

- Immediate publication on acceptance

- Inclusion in PubMed, CAS, Scopus and Google Scholar

- Research which is freely available for redistribution

Submit your manuscript at www.biomedcentral.com/submit 